\title{
Perfil agronômico, fermentativo e bromatológico da silagem obtida do consórcio entre milho e soja
}

Agronomic, fermentative and bromatological profile of silage from intercropping between corn and soybean

Perfil agronómico, fermentativo y bromatológico del ensilaje obtenido del consorcio entre maíz y soja

\section{Resumo}

O consórcio de milho com leguminosas pode aumentar a qualidade da silagem e resultar em maior produtividade animal. Objetivou-se nesta pesquisa avaliar aspectos agronômicos das culturas consorciadas entre milho e soja, perfil fermentativo e bromatológico da silagem produzida, em função do arranjo espacial das plantas e tipos de adubação. Foram realizados dois ensaios com dois arranjos espaciais: ensaio 1 - arranjo simples com uma linha de milho alternada com uma linha de soja; ensaio 2 - arranjo duplo com duas linhas de milho alternada com uma linha de soja. $\mathrm{O}$ delineamento foi em blocos ao acaso em esquema fatorial $2 \times 2+1$, com quatro repetições. O primeiro fator constou de duas modalidades de adubação de semeadura na linha: somente no milho e em área total. $\mathrm{O}$ segundo fator pelas doses de 100 e $70 \mathrm{~kg} \mathrm{ha}^{-1}$ de $\mathrm{P}_{2} \mathrm{O}_{5}$ e $\mathrm{K}_{2} \mathrm{O}$, respectivamente; e de 150 e $95 \mathrm{~kg} \mathrm{ha}^{-1}$ de $\mathrm{P}_{2} \mathrm{O}_{5}$ e $\mathrm{K}_{2} \mathrm{O}$, respectivamente. $\mathrm{O}$ monocultivo de milho foi a testemunha. Após a colheita, o material foi ensilado por 60 dias. Não houve diferença estatística no rendimento de silagem entre tratamentos, apenas aumentos na produção de vagens de soja e na qualidade da silagem nas doses maiores de adubação. Os resultados mostram que a adição de soja na silagem de milho ocasiona maiores perdas durante o processo de fermentação, mas em contrapartida eleva os teores de proteína, extrato etéreo e de digestibilidade. Ressalta-se que um volumoso com essas características pode vir a suprir a suplementação proteica em dietas de ruminantes.

Palavras-chave: Adubação de semeadura; Fósforo; Potássio; Volumoso.

\begin{abstract}
The corn and soybean intercropping can increase the quality of the silage and result in higher animal productivity. This research aimed to evaluate the agronomic aspects of intercropped corn + soybean, fermentative and bromatological profile of the intercropping silage, in function of the plant spatial arrangement, and types of fertilization. Two tests were performed; test 1: being in simple arrangement (a corn line alternated with a soybean line); test (2) in double arrangement (two corn lines alternated with a soybean line). The experimental design was a randomized block design in a $2 \times 2+1$ factorial scheme, with four replications. The first factor was constituted of two sowing fertilization modalities in the line: only in corn, and in total area; the second factor, were the seeding fertilization types: 100 and $70 \mathrm{~kg} \mathrm{ha}^{-1} \mathrm{P}_{2} \mathrm{O}_{5}$ and $\mathrm{K}_{2} \mathrm{O}$, respectively (Dose 1) and 150 and $95 \mathrm{~kg} \mathrm{ha}^{-1}$ of $\mathrm{P}_{2} \mathrm{O}_{5}$ and $\mathrm{K}_{2} \mathrm{O}$, respectively (Dose 2). The additional treatment corresponded to corn monoculture. After harvesting, the material was ensiled for 60 days. There was no statistical difference in the yield of silage between treatments, only increases in the production of soybean pods and in the quality of the silage in the higher doses of fertilization. The results show that the soybean addition in corn silage causes greater losses during the fermentation process, but in contrast increases the
\end{abstract}


protein and ether extract contents and digestibility. Pointing out that a roughage with these characteristics may supply protein supplementation in ruminant diets.

Keywords: Seeding fertilizer; Phosphorus; Potassium; Bulky.

\section{Resumen}

El consorcio de maíz con leguminosas puede incrementar la calidad del ensilaje y resultar en una mayor productividad animal. Esta investigación propone evaluar aspectos agronómicos de cultivos intercalados de maíz + soja, perfil fermentativo y bromatológico del ensilaje consorcio, dependiendo de la disposición espacial de las plantas y tipos de fertilización. Se llevaron a cabo dos pruebas; prueba 1: estar en una disposición simple (una línea de maíz alternada con una línea de soja); prueba 2: en disposición doble (dos líneas de maíz alternadas con una línea de soja). El diseño fue en bloques al azar en un esquema factorial $2 \times 2+1$, con cuatro repeticiones. El primer factor consistió en dos tipos de fertilización de siembra en fila: solo en maíz y en área total; el segundo factor: 100 y $70 \mathrm{~kg} \mathrm{ha}^{-1} \mathrm{de}_{2} \mathrm{P}_{2} \mathrm{O}_{5}$ y $\mathrm{K}_{2} \mathrm{O}$ y 150 y $95 \mathrm{~kg} \mathrm{ha}^{-1}$ de $\mathrm{P}_{2} \mathrm{O}_{5}$ y $\mathrm{K}_{2} \mathrm{O}$. El tratamiento adicional correspondió al monocultivo de maíz. Después de la cosecha, el material se ensiló durante 60 días. No hubo diferencia estadística en el rendimiento de ensilaje entre tratamientos, solo incrementos en la producción de vainas de soja y en la calidad del ensilaje en las dosis más altas de fertilización. Los resultados muestran que la adición de soja en el ensilado de maíz provoca mayores pérdidas durante el proceso de fermentación, pero por otro lado aumenta los niveles de proteína y extracto etéreo y digestibilidad. Haciendo hincapié en que un forraje con estas características puede aportar suplementos proteicos en las dietas de rumiantes.

Palabras clave: Fertilización de la siembra; Fósforo; Potasio; Voluminoso.

\section{Introdução}

Consórcio é o cultivo simultâneo de mais de uma espécie na mesma área (Brooker, et al., 2015) e a principal finalidade é obter maior produtividade total por unidade de área e tempo (Liu, et al., 2017). Um dos aspectos mais alusivos ao cultivo consorciado e praticamente tem sido pouco estudado é a adubação das culturas envolvidas. A exigência nutricional das espécies consortes pode ser modificada, como resultado da interação entre plantas, em comparação a adubação dos monocultivos.

De acordo com Cunha et al. (2014), na maioria dos estudos são utilizadas, como adubação de plantio do consórcio, as doses de nutrientes recomendadas para a monocultura. No consórcio, a soja fornece nitrogênio através da fixação biológica (FBN), que atende a sua própria exigência e serve como um meio importante e de baixo custo para a melhoria da fertilidade do solo (Ijoyah \& Fanen, 2012). Porém, o nitrogênio atmosférico fixado pela leguminosa não atende as exigências da cultura consorte e além disto existe a necessidade de adubações com outros nutrientes e em quantidades elevadas, principalmente com fontes fosfatadas e potássicas.

O fósforo apresenta funções essenciais no desenvolvimento vegetal, participando da fotossíntese, respiração, divisão e crescimento celular e principalmente no fornecimento de energia, resultando no maior crescimento e desenvolvimento inicial. É um importante nutriente, especialmente em solos do cerrado, pois a disponibilidade desse elemento, em situações naturais, é baixa (Sousa \& Lobato, 2004; Vieira, et al., 2014). Já o potássio está ligado a maior resistência das plantas quando submetidas a condições adversas, como baixa disponibilidade de água e de temperaturas extremas (Malavolta, et al., 1997).

Corrigidos nutricionalmente, os consórcios respondem com maiores índices de produção e de rendimentos das culturas consortes, podendo ser destinado para alimentação animal. Uma alternativa para o uso do consórcio entre milho e soja, é a produção de silagem. A adoção da silagem como estratégia alimentar é cada vez mais empregada em sistemas intensivos de produção de carne e leite, uma vez que permite a armazenagem de grandes quantidades de alimento volumoso para o fornecimento aos animais, principalmente em períodos em que a forragem é escassa ou de baixa qualidade (Klein, et al., 2018).

As silagens de gramíneas, apresentam baixo teor de proteína, limitando o seu uso. Portanto, um recurso para melhorar o valor nutritivo do material ensilado é a inclusão de plantas mais proteicas (Stella, et al., 2016). A utilização da soja para produção de silagem é uma alternativa viável, por apresentar alto teor proteico e apresenta características favoráveis para a produção de silagem, como capacidade de produção em diferentes regiões ecológicas, porte ereto que facilita a mecanização na 
colheita, alta concentração de minerais e alta produtividade (Rigueira, et al., 2015).

O uso da soja na silagem mista com milho para alimentação de ruminantes pode ser opção em reduzir os custos com o concentrado proteico, mantendo a dieta balanceada para melhor resposta animal. Portanto, a soja consorciada com milho pode ser uma alternativa para aumentar a produtividade das culturas e melhorar a qualidade da silagem. Nesta pesquisa avaliou-se os aspectos agronômicos das culturas consorciadas milho e soja, perfil fermentativo e bromatológico da silagem em função do arranjo espacial das plantas, e tipos de adubação de semeadura.

\section{Metodologia}

A pesquisa foi conduzida entre outubro de 2015 e fevereiro de 2016 no Instituto Federal Goiano em Rio Verde, Goiás, sob as coordenadas $17^{\circ} 48^{\prime} 67^{\prime \prime} \mathrm{S}$ e $50^{\circ} 54^{\prime} 18^{\prime \prime}$ W e altitude $754 \mathrm{~m}$. A análise química do Latossolo Vermelho na camada de 0-20 $\mathrm{cm}$, feita antes da implantação dos ensaios, apresentou: $\mathrm{pH}\left(\mathrm{em} \mathrm{CaCl}_{2}\right)=5,30 ; \mathrm{P}=13,1 \mathrm{mg} \mathrm{dm}^{-3} ; \mathrm{K}=181 \mathrm{mg} \mathrm{dm}^{-3} ; \mathrm{Ca}=4,64$ $\mathrm{cmol}_{\mathrm{c}} \mathrm{dm}^{-3} ; \mathrm{Mg}=2,50 \mathrm{cmol}_{\mathrm{c}} \mathrm{dm}^{-3} ; \mathrm{Al}=0,04 \mathrm{cmol}_{\mathrm{c}} \mathrm{dm}^{-3} ; \mathrm{MO}=3,20 \mathrm{~g} \mathrm{dm}^{-3} ; \mathrm{V} \%=62,80 ; \mathrm{Cu}=2,3 \mathrm{mg} \mathrm{dm}^{-3} ; \mathrm{Fe}=13 \mathrm{mg} \mathrm{dm}^{-3} ;$ $\mathrm{Mn}=59,7 \mathrm{mg} \mathrm{dm}^{-3} ; \mathrm{Zn}=4,5 \mathrm{mg} \mathrm{dm}^{-3} ; \mathrm{CTC}=12,1 \mathrm{cmol}_{\mathrm{c}} \mathrm{dm}^{-3} \mathrm{e}$ granulometria de 645,100 e $255 \mathrm{~g} \mathrm{~kg}^{-1}$ de argila, silte e areia, respectivamente. Os dados climatológicos do período de condução da pesquisa são apresentados na Figura 1.

Figura 1. Médias mensais de precipitação, temperaturas máxima e mínima e umidade relativa do ar (UR), durante o período de outubro de 2015 a fevereiro de 2016, em Rio Verde - GO.

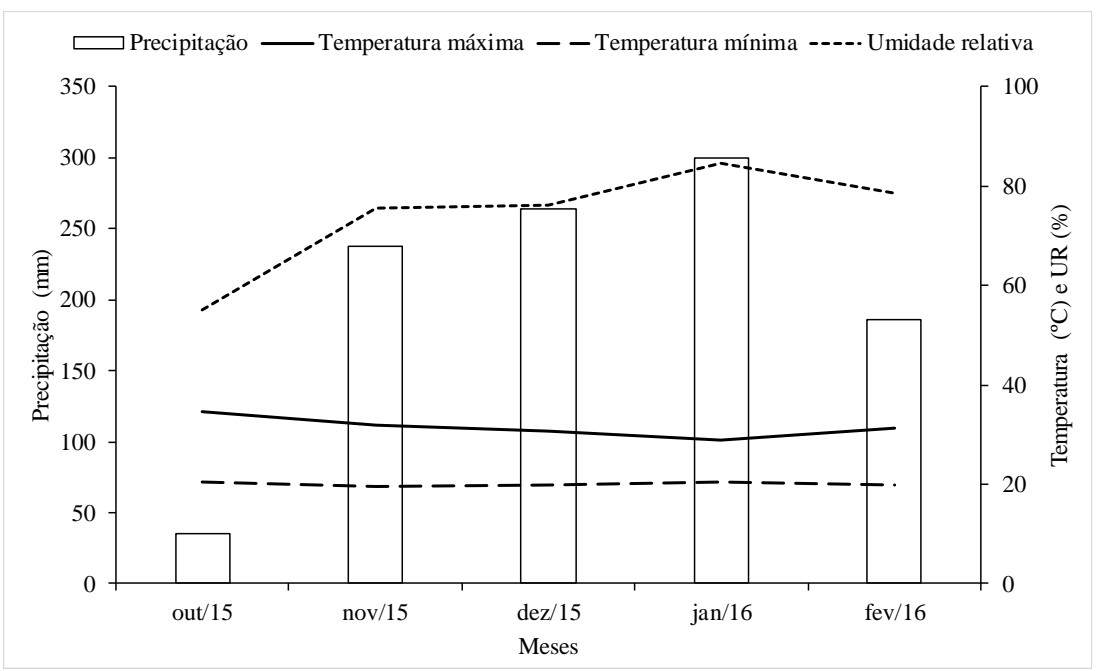

Fonte: Autores (2021).

Nesta pesquisa de natureza quantitativa (Pereira, et al., 2018) foram conduzidos dois ensaios simultaneamente, sendo: Ensaio (1) caracterizado pelo arranjo de uma linha de milho intercalada com uma linha de soja, com o milho espaçado $1 \mathrm{~m}$ entre fileiras com 6 plantas por metro linear e a soja com 20 plantas por metro linear. Ensaio (2) caracterizado pelo arranjo de duas linhas de milho (fileiras duplas) intercalado com uma linha de soja, com população de plantas de milho com 3,75 plantas por metro linear e com 20 plantas por metro linear de soja, em espaçamento único de 0,50 m entre fileiras.

O delineamento utilizado em ambos os ensaios foi de blocos casualizados, com tratamentos arranjados no esquema fatorial $2 \times 2+1$, com quatro repetições. O primeiro fator constou de duas modalidades de adubação de semeadura na linha das plantas consorciadas: somente no milho (AM), omitindo a soja; e em área total (AT). O segundo fator foi constituído por duas doses da formulação do adubo relativos a $\mathrm{P}_{2} \mathrm{O}_{5}$ e $\mathrm{K}_{2} \mathrm{O}$ usados no consórcio: $100 \mathrm{~kg} \mathrm{ha}^{-1}$ de $\mathrm{P}_{2} \mathrm{O}_{5}$ e $70 \mathrm{~kg} \mathrm{ha}^{-1}$ de $\mathrm{K}_{2} \mathrm{O}$; e $150 \mathrm{~kg}$ ha $^{-1}$ de $\mathrm{P}_{2} \mathrm{O}_{5}$ e $95 \mathrm{~kg} \mathrm{ha}^{-1}$ de $\mathrm{K}_{2} \mathrm{O}$, usando como fonte superfosfato simples e cloreto de potássio, respectivamente. $\mathrm{O}$ 
monocultivo do milho (MT) (testemunha) foi o tratamento adicional. Cada unidade experimental continha seis metros de largura e seis metros de comprimentos. Foram desprezadas as linhas laterais, bem como 0,50 m de ambos os lados. Entre blocos e parcelas houve separação de $1 \mathrm{~m}$.

Foi utilizado o híbrido de milho 30F53YHR (Pionner®) e a cultivar de soja M7110 IPRO (Monsoy®). A adubação de semeadura no monocultivo de milho foi de $100 \mathrm{~kg} \mathrm{ha}^{-1}$ de $\mathrm{P}_{2} \mathrm{O}_{5}$, de $70 \mathrm{~kg} \mathrm{ha}^{-1}$ de $\mathrm{K}_{2} \mathrm{O}$ e de $20 \mathrm{~kg} \mathrm{ha}^{-1} \mathrm{de} \mathrm{N}$. Em cobertura no milho solteiro e consorciado foi usado $120 \mathrm{~kg} \mathrm{ha}^{-1}$ de $\mathrm{N}$ aplicado na forma de ureia em linha no estágio $\mathrm{V}_{5}$. A variedade de soja foi inoculada com Bradyrhizobium spp e tratada com imidacloprido + tiodicarbe (CropStar®), seguindo a recomendação.

Em ambos os ensaios o controle de plantas daninhas foi feito com glifosato (Roundup 480®) aos 20 dias após a emergência (DAE) do milho na dose de 2,0 L do p.c ha ${ }^{-1}$. Também foram realizadas as aplicações dos inseticidas chlorpirifós (Lorsban $480 \mathrm{BR} 囚$ ) na dose de $600 \mathrm{~mL}$ do p.c ha ${ }^{-1}$ aos 30 DAE e de lambdacialotrina (Karate $50 \mathrm{EC} 囚$ ) na dose de $150 \mathrm{~mL}$ do p.c ha ${ }^{-1}$ aos 47 DAE para controle de lagarta e percevejo, da mistura pronta dos fungicidas piraclostrobina + epoxiconazol (Opera®) na dose de $600 \mathrm{~mL}$ do p.c ha-1 ${ }^{-1}$ aos 55 DAE para o controle da ferrugem.

O ponto de corte foi considerado quando o milho atingiu metade da linha de leite do grão no estágio farináceo-duro. $\mathrm{Na}$ área útil, dez plantas de soja e três de milho foram tomadas, e separadas para fracionar as diferentes partes folhas, caules e estruturas reprodutivas. Após foram pesadas separadamente para obtenção do peso verde.

As plantas de milho e soja foram colhidas na área útil e foram determinadas a massa fresca total, sendo posteriormente picadas em ensiladeira estacionária. A massa ensilada foi armazenada em silos experimentais, confeccionados em PVC com dimensão de 0,4 m de comprimento e $0,1 \mathrm{~m}$ de diâmetro. Dentro de cada silo foi colocado 500 gramas de areia seca em estufa de ventilação forçada para retirar toda umidade, para quantificar as perdas por efluentes. As amostras das plantas de soja e de milho dos diversos tratamentos foram picadas em partículas de tamanho médio de aproximadamente $2 \mathrm{~cm}$, sendo a forragem picada colocada em silos em lâminas de $10 \mathrm{~cm}$ e compactadas.

Os silos foram fechados, vedados e armazenados por 60 dias. Após a fermentação, os silos foram abertos e o material retirado foi homogeneizado. De cada silo foi separada uma alíquota de $500 \mathrm{~g}$, que foi para a estufa de ventilação forçada a $55^{\circ} \mathrm{C}$, para determinação da massa seca. Após a secagem estas foram trituradas em moinhos tipo Willey e determinou-se a composição bromatológica.

As variáveis bromatológicas mensuradas foram: lignina pelo método (Van Soest \& Robertson, 1985), fibra em detergente neutro (FDN) pelo método de Mertens (2002), matéria seca (MS), extrato etéreo (EE), material mineral (MM), fibra em detergente ácido (FDA), proteína bruta (PB) e a variável de fermentação pH, foram feitas conforme procedimentos descritos pelo método AOAC (1990). As análises para perdas por efluentes (PE) e perdas por gases (PG) foram realizadas de acordo com a metodologia descrita por Jobim (2007).

Para a digestibilidade in vitro da MS (DIVMS) foi utilizada a metodologia descrita por (Tilley \& Terry, 1963), modificada para o Fermentador Ruminal DAISY II, seguindo-se a metodologia apresentada no manual de utilização do equipamento ANKOM ${ }^{\circledR}$ Technology, fornecida pelo fabricante. Os teores de nutrientes digestíveis totais (NDT) foram obtidos via equação sugerida por Bolsen et al. (1996). Os teores de carboidratos não fibrosos (CNF) foram obtidos via equação sugerida por Mertens (2002). Ácido butírico (BUT), foi determinado por cromatografia gasosa.

Os resultados foram submetidos à análise de variância e as médias comparadas pelo teste de Tukey e de Dunnett, quando necessário. A testemunha comparativa para o teste de Dunnett foi a silagem oriunda do monocultivo de milho. A taxa de significância adotada foi de 5\%. As análises estatísticas foram realizadas por meio do software Assistat versão 7.7 beta.

A análise bromatológica das plantas antes da ensilagem em ambos os ensaios são apresentados na Tabela 1. 
Tabela 1. Análise bromatológica da massa triturada que foi ensilada referente as variáveis matéria seca (MS), fibra em detergente ácido (FDA), fibra em detergente neutro (FDN), lignina (LIG), matéria mineral (MM), proteína bruta (PB), extrato etéreo (EE) e digestibilidade in vitro da matéria seca (DIVMS) em função dos tratamentos em ambos os ensaios.

\begin{tabular}{|c|c|c|c|c|c|c|c|c|}
\hline \multicolumn{9}{|c|}{ Ensaio 1: Consórcio no sistema de fileiras simples alternadas entre milho e soja } \\
\hline \multirow{2}{*}{ Tratamentos* } & MS & FDA & FDN & LIG & MM & PB & $\mathrm{EE}$ & DIVMS \\
\hline & \multicolumn{8}{|c|}{ - } \\
\hline AM - Dose 1 & 30,03 & 28,17 & 51,99 & 8,32 & 10,46 & 12,93 & 5,22 & 59,92 \\
\hline AM - Dose 2 & 30,16 & 28,20 & 54,12 & 8,11 & 11,28 & 14,05 & 6,15 & 60,11 \\
\hline AT - Dose 1 & 31,02 & 27,88 & 51,36 & 9,13 & 11,16 & 13,58 & 6,26 & 60,28 \\
\hline AT - Dose 2 & 30,87 & 29,09 & 60,92 & 8,64 & 10,46 & 14,29 & 5,94 & 62,26 \\
\hline MT & 33,95 & 29,53 & 47,28 & 6,86 & 4,38 & 8,27 & 3,28 & 53,14 \\
\hline \multicolumn{9}{|c|}{ Ensaio 2: Consórcio no sistema de fileiras duplas do milho alternada com a soja } \\
\hline AM - Dose 1 & 30,36 & 28,73 & 56,50 & 8,03 & 9,43 & 11,89 & 4,84 & 57,82 \\
\hline AM - Dose 2 & 30,94 & 27,81 & 56,91 & 7,85 & 9,31 & 12,19 & 5,90 & 58,98 \\
\hline AT - Dose 1 & 31,55 & 28,92 & 57,26 & 7,79 & 9,20 & 12,21 & 4,77 & 58,11 \\
\hline AT - Dose 2 & 31,29 & 27,64 & 57,89 & 8,18 & 10,84 & 13,48 & 5,17 & 60,85 \\
\hline MT & 34,59 & 30,02 & 50,15 & 6,27 & 4,12 & 7,99 & 2,82 & 53,09 \\
\hline
\end{tabular}

* AT - adubação de semeadura no milho e na soja; AM - adubação somente no milho; Dose1 - (100 e 70 kg ha-1 de $\mathrm{P}_{2} \mathrm{O}_{5}$ e $\mathrm{K}_{2} \mathrm{O}$, respectivamente); Dose 2 - (150 e $95 \mathrm{~kg} \mathrm{ha}^{-1}$ de $\mathrm{P}_{2} \mathrm{O}_{5}$ e $\mathrm{K}_{2} \mathrm{O}$, respectivamente).

Fonte: Autores (2021).

\section{Resultados e Discussão}

Considerando a produção de massa fresca total do milho e de seus componentes estruturais quando consorciado com a soja não foram observadas interações significativas entre as modalidades de adubação e as doses de adubos usados na semeadura, bem como efeitos dos tratamentos consorciados em relação à testemunha solteira, em ambos os ensaios (Tabela 2). A ausência de efeitos dos tratamentos consorciados em relação ao monocultivo de milho demonstra a vantagem da produtividade do milho quando consorciado com a soja, pela menor competição exercida pela soja. Por ser uma planta de metabolismo $\mathrm{C}_{4}$ e de maior porte, o milho exerceu maior capacidade competitiva no consórcio, principalmente por luz. Além de menor competição imposta pela soja, pode ter ocorrido também o benefício da fixação biológica de nitrogênio (FBN) da soja para o milho, como enfatizado por Zimmer et al. (2012). Segundo os autores o uso de leguminosas nesses sistemas de consórcio pode contribuir para a quantidade de forragem produzida, em função da FBN.

Os resultados observados corroboram com Batista et al. (2019) que testando vários arranjos de plantas de milho e soja para a produção de silagem, não encontraram diferenças estatísticas quando testaram uma fileira de milho alternada com uma fileira de soja ou duas fileiras de milho alternadas com uma fileira de soja para a produção de biomassa de milho, apenas menor produção de biomassa de soja, quando testaram o sistema de duplas fileiras de milho com uma de soja, sem, diminuir o rendimento de biomassa total ensilada (milho + soja). 
Tabela 2. Produção de massa fresca total (PT) e dos componentes morfológicos folhas (PF), colmo (PC), espigas (PES) e pendão (PP) de plantas de milho consorciadas com soja e em monocultivo (MT) em função dos tratamentos: AT - adubação de semeadura no milho e na soja; AM - adubação somente no milho; Dose 1 - (100 e 70 kg ha-1 de $\mathrm{P}_{2} \mathrm{O}_{5}$ e $\mathrm{K}_{2} \mathrm{O}$, respectivamente); Dose 2 - (150 e $95 \mathrm{~kg} \mathrm{ha}^{-1}$ de $\mathrm{P}_{2} \mathrm{O}_{5}$ e $\mathrm{K}_{2} \mathrm{O}$, respectivamente).

\begin{tabular}{|c|c|c|c|c|c|c|}
\hline \multirow{2}{*}{ Tratamentos } & \multicolumn{3}{|c|}{ Ensaio 1} & \multicolumn{3}{|c|}{ Ensaio 2} \\
\hline & Dose 1 & Dose 2 & Média & Dose 1 & Dose 2 & Média \\
\hline \multicolumn{7}{|c|}{ PT $\left(\mathrm{kg} \mathrm{ha}^{-1}\right)^{\mathrm{ns}}$} \\
\hline $\mathrm{AM}$ & $30.821,86$ & $42.527,42$ & $36.674,64$ & $26.249,66$ & $29.999,63$ & $28.124,65$ \\
\hline $\mathrm{AT}$ & $30.783,00$ & $34.155,18$ & $32.469,09$ & $27.327,44$ & $30.277,40$ & $28.802,42$ \\
\hline Média & $30.802,43$ & $38.341,30$ & -- & $26.788,55$ & $30.138,52$ & -- \\
\hline MT & \multicolumn{2}{|c|}{$36.732,94$} & & \multicolumn{2}{|c|}{$24.344,08$} & \\
\hline CV (\%) & \multicolumn{3}{|c|}{19,66} & \multicolumn{3}{|c|}{13,23} \\
\hline \multicolumn{7}{|c|}{$\mathrm{PF}\left(\mathrm{kg} \mathrm{ha}^{-1}\right)^{\mathrm{ns}}$} \\
\hline $\mathrm{AM}$ & $4.067,73-$ & $5.999,96+$ & $5.033,85$ & $3.716,49$ & $4.228,66$ & $3.972,58$ \\
\hline AT & $3.625,98-$ & $5.601,77+$ & $4.613,88$ & $4.482,73$ & 6387,59 & $5.435,16$ \\
\hline Média & $3.846,86$ & $5.800,87$ & -- & $4.099,61$ & $5.308,13$ & -- \\
\hline MT & \multicolumn{2}{|c|}{$5.361,13$} & & \multicolumn{2}{|c|}{$4.977,33$} & \\
\hline $\mathrm{CV}(\%)$ & \multicolumn{3}{|c|}{34,43} & \multicolumn{3}{|c|}{38,70} \\
\hline \multicolumn{7}{|c|}{$\mathrm{PC}\left(\mathrm{kg} \mathrm{ha}^{-1}\right)^{\mathrm{ns}}$} \\
\hline $\mathrm{AM}$ & $13.105,59$ & $17.561,06$ & $15.333,33$ & $11.910,24$ & $11.290,33$ & $11.600,29$ \\
\hline AT & $12.099,16$ & $14.012,68$ & $13.055,92$ & $10.486,13$ & $12.295,06$ & $11.390,60$ \\
\hline Média & $12.602,38$ & $15.786,87$ & -- & $11.198,19$ & $11.792,70$ & -- \\
\hline MT & \multicolumn{2}{|c|}{$16.308,06$} & & \multicolumn{2}{|c|}{$11.935,70$} & \\
\hline $\mathrm{CV}(\%)$ & \multicolumn{3}{|c|}{21,11} & \multicolumn{3}{|c|}{17,70} \\
\hline \multicolumn{7}{|c|}{ PES $\left(\mathrm{kg} \mathrm{ha}^{-1}\right)^{\mathrm{ns}}$} \\
\hline $\mathrm{AM}$ & $11.722,45$ & $16.102,24$ & $13.912,35$ & $9.008,80$ & $12.581,50$ & $10.795,15$ \\
\hline AT & $13.363,04$ & $12.431,05$ & $12.897,05$ & $10.390,19$ & $10.032,11$ & $10.211,15$ \\
\hline Média & $12.542,75$ & $14.266,65$ & -- & $9.699,50$ & $11.306,81$ & -- \\
\hline MT & \multicolumn{2}{|c|}{$16.308,06$} & & \multicolumn{2}{|c|}{$11.935,70$} & \\
\hline $\mathrm{CV}(\%)$ & \multicolumn{3}{|c|}{21,04} & \multicolumn{3}{|c|}{18,47} \\
\hline \multicolumn{7}{|c|}{$\mathrm{PP}\left(\mathrm{kg} \mathrm{ha}^{-1}\right)^{\mathrm{ns}}$} \\
\hline AM & 148,99 & 197,53 & 173,26 & 136,12 & 132,25 & 134,19 \\
\hline AT & 138,08 & 169,94 & 154,01 & 112,83 & 129,11 & 120,97 \\
\hline Média & 143,54 & 183,74 & -- & 124,48 & 130,68 & -- \\
\hline MT & \multicolumn{3}{|c|}{153,15} & \multicolumn{2}{|c|}{117,63} & \\
\hline $\mathrm{CV}(\%)$ & & 31,71 & & & 46,86 & \\
\hline
\end{tabular}

ns - não significativo. Ensaio 1: Consórcio no sistema de fileiras simples alternadas entre milho e soja. Ensaio 2: Consórcio no sistema de fileiras duplas do milho alternada com a soja.

Fonte: Autores (2021).

As massas frescas dos componentes estruturais das plantas de soja consorciada com milho são apresentadas na Tabela 3. Não se observou interação significativa entre modalidades de adubação na semeadura e doses de fertilizantes para a massa fresca de folhas e hastes de soja em ambos os ensaios e para a massa fresca de vagens no ensaio 2. Foi observado apenas efeitos significativos para doses de adubo sobre a produção de vagens no ensaio de milho alternada com soja em sistemas de fileiras simples, em que a maior dose de fertilizante proporcionou maior a produção de vagens (Tabela 3 ). 
Tabela 3. Produção de massa fresca de folhas (PF), de hastes (PH) e de vagens (PV) de plantas de soja consorciadas com milho em função dos tratamentos: AT - adubação de semeadura no milho e na soja; AM - adubação somente no milho; Dose 1 - (100 e $70 \mathrm{~kg} \mathrm{ha}^{-1}$ de $\mathrm{P}_{2} \mathrm{O}_{5}$ e $\mathrm{K}_{2} \mathrm{O}$, respectivamente); Dose 2 - (150 e $95 \mathrm{~kg} \mathrm{ha}^{-1}$ de $\mathrm{P}_{2} \mathrm{O} 5$ e $\mathrm{K}_{2} \mathrm{O}$, respectivamente).

\begin{tabular}{|c|c|c|c|c|c|c|}
\hline \multirow{2}{*}{ Tratamentos } & \multicolumn{3}{|c|}{ Ensaio 1} & \multicolumn{3}{|c|}{ Ensaio 2} \\
\hline & Dose 1 & Dose 2 & Média & Dose 1 & Dose 2 & Média \\
\hline \multicolumn{7}{|c|}{$\mathrm{PF}\left(\mathrm{kg} \mathrm{ha}^{-1}\right)$} \\
\hline AM & 428,75 & 453,99 & 441,37 & 380,67 & 425,70 & 403,18 \\
\hline $\mathrm{AT}$ & 379,31 & 452,21 & 415,76 & 425,26 & 254,24 & 339,75 \\
\hline Média & 404,03 & 453,10 & -- & 402,965 & 339,97 & -- \\
\hline $\mathrm{CV}(\%)$ & & 66,41 & & & 56,10 & \\
\hline \multicolumn{7}{|c|}{$\mathrm{PH}\left(\mathrm{kg} \mathrm{ha}^{-1}\right)$} \\
\hline AM & $1.089,47$ & $1.155,26$ & 1122,37 & 887,33 & 752,84 & 820,08 \\
\hline $\mathrm{AT}$ & 908,54 & 833,70 & 871,12 & 959,83 & 829,32 & 894,57 \\
\hline Média & 999,01 & 994,48 & -- & 923,58 & 791,08 & -- \\
\hline $\mathrm{CV}(\%)$ & & 44,38 & & & 33,92 & \\
\hline \multicolumn{7}{|c|}{ PV $\left(\mathrm{kg} \mathrm{ha}^{-1}\right)$} \\
\hline $\mathrm{AM}$ & 258,89 & $1.057,38$ & 658,14 & 210,02 & 588,35 & 399,185 \\
\hline AT & 268,89 & 653,82 & 461,36 & 470,47 & 381,67 & 426,07 \\
\hline Média & $263,89 \mathrm{~B}$ & $855,60 \mathrm{~A}$ & -- & 340,245 & 485,01 & -- \\
\hline $\mathrm{CV}(\%)$ & & 41,77 & & & 49,93 & \\
\hline
\end{tabular}

ns - não significativo. Médias seguidas por diferentes letras nas linhas são estatisticamente diferentes pelo teste F (p<0,05). Ensaio 1:

Consórcio no sistema de fileiras simples alternadas entre milho e soja. Ensaio 2: Consórcio no sistema de fileiras duplas do milho alternada com a soja.

Fonte: Autores (2021).

Para as frações fibrosas da silagem não foram observadas interações significativas entre os fatores para FDA, FDN e LIG em ambos os ensaios e para HEM no ensaio 1 (Tabela 4). Interações significativas foram observadas para HEM no ensaio 2 e para CEL para os dois ensaios. Para FDA, a adubação de semeadura feita somente no milho com as doses de 100 e $70 \mathrm{~kg}$ ha $^{-1}$ de $\mathrm{P}_{2} \mathrm{O}_{5}$ e $\mathrm{K}_{2} \mathrm{O}$, respectivamente, proporcionou menor valor desta variável, quando comparado ao monocultivo de milho (Tabela 4). FDN é uma importante fonte de nutrientes para ruminantes, pois estimula a ruminação e, consequentemente, a saúde do rúmen. Assim, os teores não podem ser elevados, já que esta é constituída por lignina de porção indigestível, celulose parcialmente digestível e hemicelulose (Neumann et al., 2017).

Todos os tratamentos dos consórcios tiveram valores superiores de FDN quando comparados ao monocultivo de milho (Tabela 4), e provavelmente este efeito deve-se a presença da soja na silagem mista. Na média geral, os valores de FDN foram semelhantes aos encontrados por Neumann et al. (2018), avaliando diferentes tipos de híbridos de milho para silagem. Segundo Van Soest (1994), os níveis adequados de FDN e FDA para o consumo animal devem ser respectivamente abaixo de $60 \%$ e $40 \%$, enquadrando as silagens de todos os tratamentos avaliados nesse experimento. 
Tabela 4. Porcentagem de fibra em detergente ácido (FDA), fibra em detergente neutro (FDN), lignina (LIG), hemicelulose (HEM), celulose (CEL) de silagem de soja e milho consorciados e da silagem de milho, em função dos tratamentos: AT adubação de semeadura no milho e na soja; $\mathrm{AM}$ - adubação somente no milho; Dose 1 - $\left(100\right.$ e $70 \mathrm{~kg} \mathrm{ha}^{-1}$ de $\mathrm{P}_{2} \mathrm{O}_{5}$ e $\mathrm{K}_{2} \mathrm{O}$, respectivamente); Dose 2 - (150 e $95 \mathrm{~kg} \mathrm{ha}^{-1}$ de $\mathrm{P}_{2} \mathrm{O}_{5}$ e $\mathrm{K}_{2} \mathrm{O}$, respectivamente).

\begin{tabular}{|c|c|c|c|c|c|c|}
\hline \multirow{2}{*}{ Tratamentos } & \multicolumn{3}{|c|}{ Ensaio 1} & \multicolumn{3}{|c|}{ Ensaio 2} \\
\hline & Dose 1 & Dose 2 & Média & Dose 1 & Dose 2 & Média \\
\hline \multicolumn{7}{|c|}{ FDA $(\%)$} \\
\hline AM & $26,32-$ & 27,84 & 27,08 & 26,15 & 26,87 & 26,51 \\
\hline AT & 27,08 & 28,12 & 27,60 & 26,99 & 27,58 & 27,28 \\
\hline Média & 26,70 & 27,98 & -- & 26,57 & 27,22 & -- \\
\hline MT & \multicolumn{3}{|c|}{29,56} & \multicolumn{2}{|c|}{27,98} & \\
\hline CV (\%) & \multicolumn{3}{|c|}{5,75} & \multicolumn{3}{|c|}{6,20} \\
\hline \multicolumn{7}{|c|}{ FDN $(\%)$} \\
\hline $\mathrm{AM}$ & $51,72+$ & $50,33+$ & 51,02 & $55,47+$ & $56,72+$ & 56,09 \\
\hline AT & $50,43+$ & $50,99+$ & 50,71 & $55,38+$ & $57,80+$ & 56,59 \\
\hline Média & 51,07 & 50,66 & -- & 55,42 & 57,26 & -- \\
\hline MT & \multicolumn{2}{|c|}{45,83} & & \multicolumn{2}{|c|}{48,35} & \\
\hline CV $(\%)$ & \multicolumn{3}{|c|}{3,95} & \multicolumn{3}{|c|}{4,58} \\
\hline \multicolumn{7}{|c|}{ LIG $(\%)$} \\
\hline $\mathrm{AM}$ & $6,41+$ & $6,26+$ & 6,33 & $6,96+$ & $5,83+$ & 6,39 \\
\hline AT & 6,16- & $5,07+$ & 5,61 & $5,34+$ & $5,41+$ & 5,87 \\
\hline Média & 6,28 & 5,66 & -- & 6,15 & 5,62 & -- \\
\hline MT & \multicolumn{3}{|c|}{4,59} & \multicolumn{2}{|c|}{4,26} & \\
\hline CV (\%) & \multicolumn{3}{|c|}{4,10} & \multicolumn{3}{|c|}{4,76} \\
\hline \multicolumn{7}{|c|}{$\operatorname{HEM}(\%)$} \\
\hline $\mathrm{AM}$ & $25,40+$ & $22,49+$ & 23,94 & $29,32 \mathrm{aB}+$ & $29,85 \mathrm{aA}+$ & 29,58 \\
\hline AT & $23,35+$ & $22,87+$ & 23,11 & $28,39 \mathrm{bA}+$ & $30,22 \mathrm{aA}+$ & 29,30 \\
\hline Média & 24,37 & 22,68 & -- & 28,85 & 30,03 & -- \\
\hline MT & \multicolumn{3}{|c|}{16,27} & \multicolumn{2}{|c|}{20,37} & \\
\hline CV (\%) & \multicolumn{3}{|c|}{4,78} & \multicolumn{3}{|c|}{4,32} \\
\hline \multicolumn{7}{|c|}{ CEL (\%) } \\
\hline $\mathrm{AM}$ & $19,91 \mathrm{bB}-$ & $21,58 \mathrm{aA}-$ & 20,74 & $19,19 \mathrm{bB}-$ & $21,04 \mathrm{bA}-$ & 20,11 \\
\hline AT & $20,92 \mathrm{aB}-$ & $23,05 \mathrm{aA}-$ & 21,98 & $21,65 \mathrm{bA}-$ & $22,17 \mathrm{aA}-$ & 21,91 \\
\hline Média & 20,41 & 22,31 & -- & 20,42 & 21,60 & -- \\
\hline MT & \multicolumn{3}{|c|}{24,97} & \multicolumn{3}{|c|}{23,72} \\
\hline CV (\%) & \multicolumn{3}{|c|}{5,45} & \multicolumn{3}{|c|}{4,86} \\
\hline
\end{tabular}

MT - monocultivo de milho. Médias seguidas por diferentes letras minúsculas nas colunas e maiúsculas nas linhas são estatisticamente diferentes pelo teste $\mathrm{F}(\mathrm{p}<0,05)$. + ou - média superior ou inferior, respectivamente, à testemunha comparativa $(\mathrm{MT})$ pelo teste de Dunnett $(\mathrm{p}<0,05)$.

Fonte: Autores (2021).

O incremento da soja elevou o teor de lignina em todos os tratamentos consorciados em relação à testemunha, o que pode desfavorecer a qualidade nutricional da silagem pelo aumento no teor desta. Stella et al. (2016), avaliando silagem de milho com inclusão de soja com 50\% de plantas de soja e 50\% de plantas de milho, obteve valores semelhantes para lignina, com aproximadamente $6 \%$. A presença de lignina contribui para aumentar a fração indigerível, reduzindo, assim, a fração potencialmente digerível (Mizubuti, et al., 2011).

A busca por elevados teores de hemicelulose, é interessante uma vez que os ruminantes desdobram esses componentes por meio de sua flora bacteriana em ácidos graxos de cadeia curta, principalmente acético, propiônico e butírico, os quais 
representam a maior fonte de energia quando a alimentação desses animais é a base de forragem (Ferreira et al., 2017). Quando os tratamentos foram implementados no sistema consorciado de fileiras duplas de milho alternado com soja (Ensaio 2) foi observado maior valor de HEM quando foi disponibilizado maior quantidade de $\mathrm{P}_{2} \mathrm{O}_{5}$ e $\mathrm{K}_{2} \mathrm{O}$ às plantas, independente da modalidade de adubação (Tabela 4), evidenciando que o aumento da adubação contribuiu para a qualidade da silagem. Por outro lado, quando foi usado a menor dose de adubação de semeadura (100 e $70 \mathrm{~kg} \mathrm{ha}^{-1}$ de $\mathrm{P}_{2} \mathrm{O}_{5}$ e $\mathrm{K}_{2} \mathrm{O}$, respectivamente), o incremento na HEM foi observado somente quando a adubação foi realizada conjuntamente nas culturas consorciadas (Tabela 4).

O teor de celulose (CEL) em ambos os ensaios apresentou valores superiores quando foram utilizadas as maiores doses de fertilizante, independente da modalidade de fornecimento deste adubo (Tabela 4). Os consórcios obtiveram valores menores quando comparados com o monocultivo do milho. Maiores valores de CEL foram observados quando a adubação foi feita em área total. Mesmo comportamento foi observado em silagens de milho em diferentes alturas de corte e uso de inoculantes por Marquardt et al. (2017). De modo geral, o conteúdo de fibras é um dos principais fatores que limitam o valor nutritivo da silagem (Krakowsky, et al., 2006).

Quanto às variáveis fermentativas do processo de ensilagem foi observada interação significativa para a perda por gases (PG) no ensaio 2 e para o teor de ácido butírico (BUT) no ensaio 1 (Tabela 5). 
Tabela 5. Perdas por efluentes, perdas por gases, $\mathrm{pH}$ e ácido butírico (BUT) da silagem de soja e milho consorciados e da silagem de milho, em função dos tratamentos: AT - adubação de semeadura no milho e na soja; AM - adubação somente no milho; Dose 1 - (100 e $70 \mathrm{~kg} \mathrm{ha}^{-1}$ de $\mathrm{P}_{2} \mathrm{O}_{5}$ e $\mathrm{K}_{2} \mathrm{O}$, respectivamente); Dose 2 - (150 e $95 \mathrm{~kg}^{-1}$ de $\mathrm{P}_{2} \mathrm{O}_{5}$ e $\mathrm{K}_{2} \mathrm{O}$, respectivamente).

\begin{tabular}{|c|c|c|c|c|c|c|}
\hline \multirow{2}{*}{ Tratamentos } & \multicolumn{3}{|c|}{ Ensaio 1} & \multicolumn{3}{|c|}{ Ensaio 2} \\
\hline & Dose 1 & Dose 2 & Média & Dose 1 & Dose 2 & Média \\
\hline \multicolumn{7}{|c|}{ PG (\%) } \\
\hline AM & $8,36+$ & $7,34+$ & 7,85 & $8,03 \mathrm{aA}+$ & $5,62 \mathrm{bB}+$ & 6,82 \\
\hline AT & $7,94+$ & $6,95+$ & 7,44 & 7,89aA+ & $6,56 \mathrm{aB}+$ & 7,22 \\
\hline Média & 8,15 & 7,14 & -- & 7,96 & 6,09 & -- \\
\hline MT & \multicolumn{3}{|c|}{4,57} & \multicolumn{2}{|c|}{3,38} & \\
\hline CV (\%) & \multicolumn{3}{|c|}{12,40} & \multicolumn{3}{|c|}{10,29} \\
\hline \multicolumn{7}{|c|}{ PE (\%) } \\
\hline $\mathrm{AM}$ & $6,37+$ & $5,25+$ & 5,81 & $6,02+-$ & $5,38-$ & 5,70 \\
\hline AT & $5,83+$ & $5,54+$ & 5,68 & $5,94+$ & $5,66+$ & 5,80 \\
\hline Média & 6,10 & 5,39 & -- & 5,98 & 5,84 & -- \\
\hline MT & \multicolumn{3}{|c|}{4,05} & \multicolumn{3}{|c|}{3,78} \\
\hline $\mathrm{CV}(\%)$ & \multicolumn{3}{|c|}{8,44} & \multicolumn{3}{|c|}{9,12} \\
\hline
\end{tabular}

\begin{tabular}{|c|c|c|c|c|c|c|}
\hline \multicolumn{7}{|c|}{$\mathrm{pH}(\%)$} \\
\hline AM & $4,96+$ & $5,89+$ & 5,42 & $4,15+$ & $4,39+$ & 4,27 \\
\hline AT & $4,77+$ & $4,90+$ & 4,83 & 4,28 & $3,91+$ & 4,09 \\
\hline Média & 4,86 & 5,39 & -- & 4,21 & 4,15 & -- \\
\hline MT & \multicolumn{3}{|c|}{3,57} & \multicolumn{2}{|c|}{3,33} & \\
\hline $\mathrm{CV}(\%)$ & \multicolumn{3}{|c|}{4,65} & \multicolumn{3}{|c|}{5,36} \\
\hline \multicolumn{7}{|c|}{ BUT (\%) } \\
\hline AM & $0,30 \mathrm{aA}+$ & $0,28 \mathrm{aA}+$ & 0,29 & $0,17+$ & $0,17+$ & 0,17 \\
\hline AT & $0,25 \mathrm{bB}+$ & $0,28 \mathrm{aA}+$ & 0,26 & $0,19+$ & $0,15+$ & 0,17 \\
\hline Média & 0,27 & 0,28 & -- & 0,18 & 0,16 & -- \\
\hline MT & \multicolumn{3}{|c|}{0,05} & \multicolumn{3}{|c|}{0,04} \\
\hline $\mathrm{CV}(\%)$ & \multicolumn{3}{|c|}{17,74} & \multicolumn{3}{|c|}{19,20} \\
\hline
\end{tabular}

MT - monocultivo de milho. Médias seguidas por diferentes letras minúsculas nas colunas e maiúsculas nas linhas são estatisticamente diferentes pelo teste $\mathrm{F}(\mathrm{p}<0,05)$. + média superior à testemunha comparativa $(\mathrm{MT})$ pelo teste de Dunnett $(\mathrm{p}<0,05)$.

Fonte: Autores (2021).

Não foram observados efeitos para a interação ou efeitos isolados para perdas por efluentes (PE) e pH em ambos os ensaios e PG no ensaio 1 e BUT no ensaio 2 (Tabela 5). Especificamente, menor valor de PG foi observado no ensaio 2, com o uso da maior dose do fertilizante fornecida somente no milho (Tabela 5). Comparativamente à testemunha, os tratamentos consorciados tiveram maiores valores de PG, PE e pH. No momento da ensilagem observou-se que a silagem com incremento de soja tende a ficar mais úmida e houve maior porcentagem de perdas por efluentes e gases quando comparado à testemunha do milho. Senger et al. (2005) também observaram resultados semelhantes em silagens úmidas, com maiores perdas por gases e efluentes

Em relação ao pH, as silagens exclusivamente de leguminosas tendem a ter valor elevado, e pode comprometer a silagem, pois propiciam a presença de microrganismos indesejáveis e alto teor de ácido butírico. Este comportamento deve-se a um conjunto de fatores, como maior teor de umidade no momento da ensilagem e menor teor de carboidratos altamente fermentáveis, os quais são importantes para o crescimento das bactérias lácticas responsáveis pela diminuição do pH (Stella, et 
al., 2016). Valores de pH abaixo de 4 indicam que o processo fermentativo foi satisfatório (Queiroz, et al., 2012).

A adição de soja na silagem promoveu maiores teores de BUT em relação a silagem exclusiva de milho (Tabela 5). Para o ensaio 1, a menor concentração de BUT foi observado quando se utilizou a menor dose do fertilizante em área total em relação aos demais tratamentos. O butirato encontrado na silagem indica a presença de microrganismos indesejáveis, portanto níveis elevados comprometem a qualidade da silagem, a concentração desse ácido na MS da silagem deve ser inferior a 0,2\% (Negrão, et al., 2016).

Na Tabela 6 são apresentados os valores de MM, PB e EE e observa-se que houve interação significativa somente para EE no ensaio 1. Menor valor de EE foi observado na menor dose de adubo utilizada e quando foi realizada somente no milho. Valores de EE devem estar em torno de 5\%, maiores que isso limita o consumo animal (Martin, et al., 2012). Valores elevados de EE causam problemas de função ruminal devido ao poder deletério dos ácidos graxos insaturados (Xin \& Yu, 2013). Mas, teores equilibrados podem auxiliar na mitigação de metano entérico pelos ruminantes (Morgavi, et al., 2012).

Tabela 6. Teores de matéria mineral (MM), proteína bruta (PB), extrato etéreo (EE) de silagem de soja e milho consorciados e da silagem de milho, em função dos tratamentos: AT - adubação de semeadura no milho e na soja; AM - adubação somente no milho; Dose 1 - (100 e $70 \mathrm{~kg} \mathrm{ha}^{-1}$ de $\mathrm{P}_{2} \mathrm{O}_{5}$ e $\mathrm{K}_{2} \mathrm{O}$, respectivamente); Dose 2 - (150 e $95 \mathrm{~kg} \mathrm{ha}^{-1}$ de $\mathrm{P}_{2} \mathrm{O}_{5}$ e $\mathrm{K}_{2} \mathrm{O}$, respectivamente).

\begin{tabular}{|c|c|c|c|c|c|c|}
\hline \multirow{2}{*}{ Tratamentos } & \multicolumn{3}{|c|}{ Ensaio 1} & \multicolumn{3}{|c|}{ Ensaio 2} \\
\hline & Dose 1 & Dose 2 & Média & Dose 1 & Dose 2 & Média \\
\hline \multicolumn{7}{|c|}{ MM (\%) } \\
\hline $\mathrm{AM}$ & $9,65+$ & $10,37+$ & 10,01 & $7,93+$ & $8,05+$ & 7,99 \\
\hline AT & $9,49+$ & $9,98+$ & 9,73 & $8,18+$ & $8,99+$ & 8,58 \\
\hline Média & 9,57 & 10,17 & -- & 8,05 & 8,52 & -- \\
\hline MT & \multicolumn{3}{|c|}{3,84} & \multicolumn{2}{|c|}{3,12} & \\
\hline $\mathrm{CV}(\%)$ & \multicolumn{3}{|c|}{8,49} & \multicolumn{3}{|c|}{9,17} \\
\hline \multicolumn{7}{|c|}{ PB (\%) } \\
\hline $\mathrm{AM}$ & $12,53+$ & $13,86+$ & 13,19 & $11,27+$ & $11,09+$ & 11,18 \\
\hline AT & $11,64+$ & $13,91+$ & 12,77 & $11,06+$ & $10,57+$ & 10,81 \\
\hline Média & 12,08 & 13,88 & -- & 11,16 & 10,83 & -- \\
\hline MT & \multicolumn{2}{|c|}{6,99} & & \multicolumn{2}{|c|}{6,24} & \\
\hline $\mathrm{CV}(\%)$ & \multicolumn{3}{|c|}{9,18} & \multicolumn{3}{|c|}{9,39} \\
\hline \multicolumn{7}{|c|}{$\mathrm{EE}(\%)$} \\
\hline $\mathrm{AM}$ & $4,15 \mathrm{bB}$ & $5,11 \mathrm{aA}$ & 4,63 & $4,25+$ & $5,00+$ & 4,62 \\
\hline AT & $5,03 \mathrm{aA}$ & $5,23 \mathrm{aA}$ & 5,13 & $4,65+$ & $4,89+$ & 4,82 \\
\hline Média & 4,59 & 5,17 & -- & 4,45 & 4,94 & -- \\
\hline MT & \multicolumn{3}{|c|}{2,86} & \multicolumn{2}{|c|}{1,99} & \\
\hline $\mathrm{CV}(\%)$ & \multicolumn{3}{|c|}{8,26} & \multicolumn{3}{|c|}{9,47} \\
\hline
\end{tabular}

MT - monocultivo de milho. Médias seguidas por diferentes letras minúsculas nas colunas e maiúsculas nas linhas são estatisticamente diferentes pelo teste $\mathrm{F}(\mathrm{p}<0,05)$. + ou - média superior ou inferior, respectivamente, à testemunha comparativa (MT) pelo teste de Dunnett $(\mathrm{p}<0,05)$.

Fonte: Autores (2021).

Dos três parâmetros avaliados, observa-se que os valores dos tratamentos consorciados foram superiores quando comparado ao tratamento do milho solteiro, melhorando a qualidade nutricional da silagem, uma vez que silagens somente de milho, apresentam baixo teor de matéria mineral e proteína. Desta forma, enfatiza-se que tanto a soja quanto o tipo de adubação beneficiaram a massa ensilada. Segundo Lima et al. (2013) em estudo de um silo de superfície com capacidade de 40 toneladas de silagem na matéria natural, a cada tonelada de planta de soja adicionado na silagem de sorgo foi possível 
aumentar em $2 \%$ o teor de PB. No ensaio 1, a adubação na linha do milho em dose cheia, e a inclusão da soja beneficiou a silagem produzida, com $11,37 \%$ de MM, uma vez que a planta de soja é rica em minerais (principalmente cálcio e fósforo) (Stella, et al., 2016).

De acordo com Carvalho et al. (2015) na avaliação de diversos híbridos de milho destinado a produção de silagem, os autores obtiveram médias para MM, PB e EE inferiores a encontradas nesse trabalho. Segundo Assad et al. (2015) o teor proteico na fermentação microbiana efetiva no rúmen requer uma quantidade mínima de $7 \%$ de proteína bruta no alimento, sendo então a silagem mista de milho+soja, uma opção de volumoso de qualidade proteica.

Na Tabela 7 os teores de MS, NDT e CNF não foram encontradas interações significativas em ambos os ensaios.

Tabela 7. Teores de matéria seca (MS), nutrientes digestíveis totais (NDT), carboidratos não fibrosos (CNF) e digestibilidade in vitro da matéria seca (DIVMS) de silagem de soja e milho consorciados e da silagem de milho, em função dos tratamentos: AT - adubação de semeadura no milho e na soja; AM - adubação somente no milho; Dose 1 - $\left(100\right.$ e 70 kg ha ${ }^{-1}$ de $\mathrm{P}_{2} \mathrm{O}_{5}$ e $\mathrm{K}_{2} \mathrm{O}_{\text {, }}$ respectivamente); Dose 2 - (150 e $95 \mathrm{~kg} \mathrm{ha}^{-1}$ de $\mathrm{P}_{2} \mathrm{O}_{5}$ e $\mathrm{K}_{2} \mathrm{O}$, respectivamente).

\begin{tabular}{|c|c|c|c|c|c|c|}
\hline \multirow{2}{*}{ Tratamentos } & \multicolumn{3}{|c|}{ Ensaio 1} & \multicolumn{3}{|c|}{ Ensaio 2} \\
\hline & Dose 1 & Dose 2 & Média & Dose 1 & Dose 2 & Média \\
\hline \multicolumn{7}{|c|}{ MS (\%) } \\
\hline AM & 28,90 & 29,48 & 29,19 & 29,37 & 30,19 & 29,78 \\
\hline $\mathrm{AT}$ & 29,55 & 28,16 & 28,85 & 30,46 & 30,99 & 30,72 \\
\hline Média & 29,22 & 28,82 & -- & 29,91 & 30,59 & -- \\
\hline MT & \multicolumn{2}{|c|}{32,16} & & \multicolumn{2}{|c|}{32,83} & \\
\hline $\mathrm{CV}(\%)$ & \multicolumn{3}{|c|}{8,92} & \multicolumn{3}{|c|}{8,51} \\
\hline \multicolumn{7}{|c|}{ NDT (\%) } \\
\hline AM & 69,42 & 68,36 & 68,89 & 69,54 & 69,04 & 69,29 \\
\hline $\mathrm{AT}$ & 68,89 & 68,16 & 68,52 & 68,95 & 68,54 & 68,74 \\
\hline Média & 69,15 & 68,26 & -- & 69,24 & 68,79 & -- \\
\hline MT & \multicolumn{2}{|c|}{67,15} & & \multicolumn{2}{|c|}{68,26} & \\
\hline $\mathrm{CV}(\%)$ & \multicolumn{3}{|c|}{9,21} & \multicolumn{3}{|c|}{8,03} \\
\hline \multicolumn{7}{|c|}{ CNF (\%) } \\
\hline $\mathrm{AM}$ & $21,95-$ & $20,33-$ & 21,14 & $21,08-$ & $19,14-$ & 20,11 \\
\hline AT & $23,41-$ & $19,89-$ & 21,65 & $20,73-$ & $17,75-$ & 19,24 \\
\hline Média & 22,68 & 20,11 & -- & 20,90 & 18,44 & -- \\
\hline MT & \multicolumn{2}{|c|}{40,48} & & \multicolumn{2}{|c|}{39,85} & \\
\hline $\mathrm{CV}(\%)$ & \multicolumn{3}{|c|}{8,29} & \multicolumn{3}{|c|}{12,35} \\
\hline \multicolumn{7}{|c|}{ DIVMS (\%) } \\
\hline $\mathrm{AM}$ & $56,32 \mathrm{bB}+$ & $58,03 \mathrm{aA}+$ & 57,17 & $55,18+$ & $56,47+$ & 55,82 \\
\hline $\mathrm{AT}$ & $57,55 \mathrm{bA}+$ & $59,10 \mathrm{aA}+$ & 58,32 & $56,95+$ & $57,21+$ & 57,08 \\
\hline Média & 56,93 & 58,56 & -- & 56,06 & 56,84 & -- \\
\hline MT & \multicolumn{2}{|c|}{51,36} & & \multicolumn{2}{|c|}{50,48} & \\
\hline $\mathrm{CV}(\%)$ & \multicolumn{3}{|c|}{5,70} & \multicolumn{3}{|c|}{4,92} \\
\hline
\end{tabular}

MT - monocultivo de milho. Médias seguidas por diferentes letras minúsculas nas colunas e maiúsculas nas linhas são estatisticamente diferentes pelo teste $\mathrm{F}(\mathrm{p}<0,05)$. + ou - média superior ou inferior, respectivamente, a testemunha comparativa (MT) pelo teste de Dunnett $(\mathrm{p}<0,05)$.

Fonte: Autores (2021).

Para DIVMS no ensaio 2 não houve interações significativas, já a DIVMS no ensaio 1 houve interação significativa. 
Pode-se notar que a inclusão da soja não alterou os resultados de MS e NDT em relação a silagem exclusiva de milho. A MS é uma variável fundamental para avaliar a qualidade da silagem. Nussio et al. (2001) afirmam que uma boa silagem deve conter aproximadamente 30\% de matéria seca. Martin et al. (2012), avaliando silagens de milho com diferentes tipos de irrigação encontraram resultados semelhantes ao desta pesquisa com 27,35\% de MS.

NDT é um componente muito importante a ser observado nas dietas para animais de produção, uma vez que a energia e proteína são frequentemente os fatores mais limitantes para ruminantes (Oliveira, et al., 2019). Segundo Keplin (1992) para adequado teor energético, a silagem deve apresentar entre 64 a 70\% de NDT e, portanto, a silagens apresentadas nesse estudo estão na faixa adequada.

Existem componentes que determinam o valor energético dos alimentos utilizados nas dietas de ruminantes como os CNF (Campos, et al., 2015). Neste trabalho, pode-se observar na Tabela 7, que a inclusão da soja reduziu os teores de CNF, quando se compara com a silagem do milho, e isso pode estar associado a menor participação de grão de milho na silagem. Cabral et al. (2002), avaliando a participação de porcentagens de milho em silagem, obtiveram valores inferiores ao presente estudo (15,35\%), quando foi acrescentado a porcentagem de mínima de grãos de milho.

Os maiores valores de DIVMS no ensaio 1 foi na adubação quando se utilizou a maior dose de fertilizante (Tabela 7). No ensaio 2 não houve diferença significativa entre os tratamentos avaliados, o que também foi observado por Eichelberger et al. (1997) na DIVMS, quando incluíram até 50\% de planta de soja na ensilagem de milho, e associaram à possibilidade de maior teor de FDA na silagem com a inclusão de planta de soja.

\section{Conclusão}

Milho alternado com soja em sistemas de fileiras simples e maior dose de fertilizante proporcionou a maior produção de vagens de soja consorciada com milho. A adição de planta de soja na ensilagem de milho aumenta consideravelmente os níveis proteicos.

Sob o ponto de vista da composição química, a planta de soja pode ser adicionada na ensilagem de milho, trazendo melhorias ao produto final.

Aceitabilidade e o desempenho dos animais com a inclusão de planta de soja na ensilagem de forrageiras tropicais e fatores econômicos devem ser avaliados para comprovar o seu uso como alternativa na alimentação de ruminantes.

\section{Agradecimentos}

Ao Instituto Federal Goiano, Campus Rio Verde, pelo apoio financeiro.

\section{Referências}

Assad, L. V. F., Zervoudakis, J. T., Cabral, L. S., Hatamoto-Zervoudakis, L. K., Silva-Marques, R. P., Koscheck, J. F. W., \& Micheletti, M. V. (2015) Proteína degradável no rúmen e frequência de suplementação para recria de novilhos em pastejo. Semina: Ciências Agrárias, 36, 2119-2130. 10.5433/16790359.2015v36n3Sup11p2119

Association of Official Analytical Chemists - AOAC (1990). Official methods of analysis. (15a ed.): AOAC International.

Batista, V. V., Adami, P. F., Moraes, P. V. D., Oligini, K. F., Giacomel, C. L., \& Link, L. (2019). Row arrangements of maize and soybean intercrop on silage quality and grain yield. Journal of Agricultural Science, 11(20), 286-300. 10.5539/jas.v11n2p286

Bolsen, K. K., Ashbell, G., \& Weinberg, Z. G. (1996). Silage fermentation and silage additives-Review. Journal Animal Science, 9, 483-494. 10.5713/ajas.1996.483

Brooker, R. W., Bennett, A. E., Cong, W. F., Daniell, T. J., George, T. S., Hallett, P. D., Hawes, C., Iannetta, P. P. M., Jones, H. G., Karley, A. J., Li, L., Mckenzie, B. M., Pakeman, R. J., Paterson, E., Schöb, C., Shen, J., Squire, G., Watson, C. A., Zhang, C., \& Zhang, F. (2015). Improving intercropping: a synthesis of research in agronomy, plant physiology and ecology. New Phytologist, 206, 107-117. 10.1111/nph.13132 
Cabral, L. S., Valadares, F. S. D. C., Edenio, D., Tilemahos, Z. J., Gomes, P. O., Rafael, G. V., \& Sales, P. E. (2002). Cinética ruminal das frações de carboidratos, produção de gás, digestibilidade in vitro da matéria seca e NDT estimado da silagem de milho com diferentes proporções de grãos. Revista Brasileira de Zootecnia, 31(6), 2332-2339. 10.1590/S1516-35982002000900023

Campos, P. R. D. S. S., Campos, V. F., Detmann, E., Cecon, P. R., Leão, M. I., Lucchi, B. B., \& Pereira, O. G. (2015). Consumo, digestibilidade e estimativa do valor energético de alguns volumosos por meio da composição química. Revista Ceres, 57(1), 079-086. http://www.ceres.ufv.br/ojs/index.php/ceres/article/view/3716/1415

Carvalho, A. F. G., Martin, T. N., Santos, S., Müller, T. M., \& Piran Filho, F. A. (2015). Perfil agronômico e bromatológico de silagem de milho no sudoeste do Paraná. Revista de la Facultad de Agronomía, 114(21), 149-159. https://dialnet.unirioja.es/servlet/articulo?codigo=5718270

Cunha, D. A., Teixeira, I. R., Jesus, F. F., Guimarães, R. T., \& Silva Teixeira, G. C. (2014). Adubação fosfatada e produção de feijão-comum e mamona em consórcio. Bioscience Journal, 30(5), 617-628. http://www.seer.ufu.br/index.php/biosciencejournal/article/view/18212/15222

Eichelberger, L., Siewerdt, L., \& Silveira Júnior, P. (1997). Efeitos da inclusão de níveis crescentes de forragem de soja e uso de inoculante na qualidade da silagem de milho. Revista Brasileira de Zootecnia, 26(5), 867-874.

Ferreira, J. P., Andreotti, M., Pascoaloto, I. M., Costa, N. R., \& Augusto, J. G. (2017). Qualidade da silagem de milho consorciado com gramíneas tropicais em diferentes espaçamentos. Boletim de Indústria Animal, 74(3), 237-245. 10.17523/bia.v74n3p237

Ijoyah, M. O., \& Fanen, F. T. (2012). Effects of different cropping pattern on performance of maize-soybean mixture in Makurdi, Nigeria. Scientific Journal of Crop Science, 1(2), 39-47.

Jobim, C. C., Nussio, L. G., Reis, R. A., \& Schmidt, P. (2007). Avanços metodológicos na avaliação da qualidade da forragem conservada. Revista Brasileira de Zootecnia, 36, 101-119. 110.1590/S1516-35982007001000013

Keplin, L. A. S. (1993). Recomendação de sorgo e milho (silagem) safra 1992/93. Revista Batavo, 8, 16-19.

Klein, J. L., Viana, A. F. P., Martini, P. M., Adams, S. M., Gusatto, C., Bona, R. A., \& Brondani, I. L. (2018). Desempenho produtivo de híbridos de milho para produção de silagem de planta inteira. Revista Brasileira de Milho e Sorgo, 17, 101-110.

Krakowsky, M. D., Lee, M., \& Coors, J. G. (2006). Quantitative trait loci for cell wall components in recombinant inbred lines of maize (Zea mays L.) II: leaf sheath tissue. Theoretical Applied Genetics, 112, 717-726. 10.1007/s00122-005-0175-0

Lima, J. A., Gavioli, I. L. C., Barbosa, C. M. P., Berndt, A., Gimenes, F. M. A., Paz, C. C. P., \& Cunha, E. A. (2013). Soybean silage and sugarcane tops silage on lamb performance. Ciência Rural, 43, 1478-1484. 10.1590/S0103-84782013005000098.

Liu, X., Rahman, T., Yang, F., Song, C., Yong, T., Liu, J., \& Yang, W. (2017). PAR interception and utilization in different maize and soybean intercropping patterns. PloS One, 12(1), e0169218, 2017. 10.1371/journal.pone.0169218

Malavolta, E., Vitti, G.C., \& Oliveira, S. A. (1997). Avaliação do estado nutricional das plantas: princípios e aplicações. (2a ed.): Potafos, 319 p.

Marquardt, F. I., Jobim, C. C., Bueno, A. V. I., \& Ribeiro, M. G. (2017). Altura de corte e adição de inoculante enzimo-bacteriano na composição químicobromatológica e digestibilidade de silagens de milho avaliada em ovinos. Ciência Animal Brasileira, 18, e-42888. 10.1590/1089-6891v18e-42888

Martin, T. N., Vieira, V. C., Menezes, L. F. G., Ortiz, S., Bertoncelli, P., \& Storck, L. (2012). Bromatological characterization of maize genotypes for silage. Acta Scientiarum. Animal Sciences, 34, 363-370. 10.4025/actascianimsci.v34i4.15271

Mertens, D. R. (2002). Gravimetric determination of amylase-treated neutral detergent fiber in feeds with refluxing in beaker or crucibles: collaborative study. Journal of AOAC International, 85(6), 1217-1240.

Mizubuti, I. Y., Ribeiro, E. L. D. A., \& Pereira, E. S. (2011). Cinética de fermentação ruminal in vitro de alguns coprodutos gerados na cadeia produtiva do biodiesel pela técnica de produção de gás. Ciência Agrária de Londrina, 32, 2021-2028. 10.5433/1679-0359.2011v32Suplp2021

Morgavi, D. P., Martin, C., Jouany, J. P., \& Ranilla, M. J. (2012). Rumen protozoa and methanogenesis: not a simple cause-effect relationship. British Journal of Nutrition, 107, 388-397. 10.1017/S0007114511002935

Negrão, F. D. M., Zanine, A. D. M., Souza, A. L. D., Cabral, L. D. S., Ferreira, D. D. J., \& Dantas, C. C. O. (2016). Perdas, perfil fermentativo e composição química das silagens de capim" Brachiaria decumbens" com inclusão de farelo de arroz. Revista Brasileira de Saúde e Produção Animal, 17(1), 13-25. $10.1590 /$ S1519-99402016000100002

Neumann, M., Horst, E. H., Dochwat, A., Venancio, B. J., Vigne, G. L. D., \& Júnior, E. S. S. (2018). Desempenho e características da carcaça de novilhos alimentados com silagem de diferentes híbridos de milho. Agrarian, 11(39), 50-58. 10.30612/agrarian.v11i39.6693

Neumann, M., Leão, G. F. M., Coelho, M. G., Figueira, D. N., Spada, C. A, \&. Perussolo, L. F. (2017). Aspectos produtivos, nutricionais e bioeconômicos de híbridos de milho para produção de silagem. Archivos de Zootecnia, 66, 51-58. 10.21071/az.v66i253.2125

Nussio, L. G., Campos, F. P., \& Dias, F. N. (2001). Importância da qualidade da porção vegetativa no valor alimentício da silagem de milho. In: Simpósio Sobre Produção e Utilização de Forragens Conservadas, 2001, Maringá. Anais: Universidade Estadual de Maringá, 127-145.

Oliveira, L. B. D., Pires, A. J. V. U., Carvalho, G. G. P. D., Ribeiro, L. S. O. U., Almeida, V. V. D., \& Peixoto, C. A. D. M. U. (2010). Perdas e valor nutritivo de silagens de milho, sorgo-sudão, sorgo forrageiro e girassol. Revista Brasileira de Zootecnia, 39(1), 61-67. 10.1590/S1516-35982010000100008

Pereira, A. S., Shitsuka, D.M., Parreira, F. J., \& Shitsuka, R. (2018). Metodologia da pesquisa científica. UFSM, NTE,

Queiroz, O. C. M., Kim, S. C, \& Adesogan, A. T. (2012). Effect of treatment with a mixture of bacteria and fibrolytic enzymes on the quality and safety of corn silage infested with different levels of rust. Journal of Dairy Science, 95(9), 5285-5291. 10.3168/jds.2012-5431 
Research, Society and Development, v. 10, n. 1, e41410111925, 2021

(CC BY 4.0) | ISSN 2525-3409 | DOI: http://dx.doi.org/10.33448/rsd-v10i1.11925

Rigueira, J. P. S., Pereira, O. G., Valadares Filho, S. C., Ribeiro, K. G., Garcia, R., \& Cezário, A. S. (2015). Soybean silage in the diet for beef cattle. Acta Scientiarum. Animal Sciences, 7, 61-65. 10.4025/actascianimsci.v37i1.25182

Senger, C. C. D., Muhlbach, P. R. F., Sánchez, L. M. B., Netto, D. P., \& Lima, L. D. D. (2005). Composição química e digestibilidade 'in vitro' de silagens de milho com distintos teores de umidade e níveis de compactação. Ciência Rural, 35(6), 1393-1399. 10.1590/S0103-84782005000600026.

Silva, F. A. S., \& Azevedo, C. A. V. (2016). The Assistat software version 7.7 and its use in the analysis of experimental data. African Journal of Agricultural Research, 11(39), 3733-3740. 10.5897/AJAR2016.11522

Sousa, D. M. G., \& Lobato, E. (2004). Cerrado: correção do solo e adubação. (2a ed.): Embrapa Informação Tecnológica, 416 p.

Stella, L. A., Peripolli, V., Prates, Ê. R., \& Barcellos, J. O. J. (2016). Composição química das silagens de milho e sorgo com inclusão de planta inteira de soja. Boletim de Indústria Animal, 73(1), 73-79. 10.17523/bia.v73n1p73

Tilley, J. M. A., \& Terry, R. A. (1963). A two stages technique for the in vitro digestion of forage crope. Journal of the British Grassland Society, 18(1), 104111.

Van Soest, P. J. (1994). Nutritional ecology of the ruminant. (2a ed.): Cornell University. 476 p.

Van Soest, P. J., \& Robertson, J. B. (1985). Analysis of forages and fibrous foods: Cornell University, 202 p.

Vieira, C. R., Weber, O. L. S, \& Scaramuzza, J. F. (2015). Saturação por bases e doses de P no crescimento e nutrição de mudas de cerejeira (Amburana Acreana Ducke). Nativa, 3(1), 01-09. 10.14583/2318-7670.v03n01a01

Xin, H., \& Yu, P. (2013). Chemical profile, energy values, and protein molecular structure characteristics of biofuel/bio-oil co-products (Carinata Meal) in comparison with canola meal. Journal of Agricultural and Food Chemistry, 61, 3926-3933. 10.1021/jf400028n

Zimmer, A., Macedo, M., Kichel, A., \& Almeida, R. D. (2012). Degradação, recuperação e renovação de pastagens: EMBRAPA Gado de Corte, 42 p. (Documentos, 189) 